\title{
Contribution of Completed Modified World Health Organization Partograph on Maternal and Foetal Mortality Reduction in Health Facilities in Makueni County, Kenya
}

\author{
Urbanus Mutiso Muthusi ${ }^{1, ~ *}$, Mokua Gladys Nyamoita ${ }^{2}$, Macharia Stephen ${ }^{3}$ \\ ${ }^{1}$ Department of Population, Reproductive Health \& Community Resource Management, Kenyatta University, Nairobi, Kenya \\ ${ }^{2}$ Department of Pharmacology, Pharmaceutical Chemistry and Pharmaceutics \& Industrial Pharmacy, Kenyatta University, Nairobi, Kenya \\ ${ }^{3}$ Department of Human Anatomy, School of Medicine, Kenyatta University, Nairobi, Kenya
}

Email address:

mutiso68@gmail.com (U. M. Muthusi),mokua.gladys@ku.ac.ke (M. G. Nyamoita), macharia.stephen@ku.ac.ke (M. Stephen)

${ }^{*}$ Corresponding author

\section{To cite this article:}

Urbanus Mutiso Muthusi, Mokua Gladys Nyamoita, Macharia Stephen. Contribution of Completed Modified World Health Organization Partograph on Maternal and Foetal Mortality Reduction in Health Facilities in Makueni County, Kenya. Central African Journal of Public Health. Vol. 5, No. 6, 2019, pp. 227-236. doi: 10.11648/j.cajph.20190506.11

Received: August 8, 2019; Accepted: September 16, 2019; Published: October 10, 2019

\begin{abstract}
Background: Maternal and foetal mortality is one of the major health problem facing low income countries as compared to the high income countries. This burden is mostly felt in sub Saharan Africa and Southeast Asia where 99\% of the global burden of maternal death is found. The World Health Organization (WHO) promotes partograph use in the monitoring and management of mothers in labour enabling timely decision-making regarding interventions to be undertaken. Objective: To assess the relationship between complete modified world health organization partograph and maternal and foetal outcomes in health facilities in Makueni County, Kenya Methods: This was a cross sectional study design. The study used a structured questionnaire to collect data from the partographs retrospectively. Data analysis was done using SPSS version 20.0 and chisquare tests were used to assess the relationship of variables. The cut off point for the level of significance was 0.05 . Phi and Cramer's V test was used to determine the strength of association Findings: Descriptive statistics and frequency tables were used to describe the extent to which the partograph was used. The use of partograph had effects on both foetal and maternal outcomes. The study established method of delivery had a significance association with foetal monitoring (foetal heart rate, liquor, and moulding), labour progress monitoring (descent, contractions and cervical dilatation) and referral monitoring at $\alpha=$ 0.05. The study also found significant association between foetal outcome and contraction, gravidity, parity, foetal heart rate and moulding at $\alpha=0.05$. Conclusion: There is a significant association between maternal, foetal outcomes and labour progress and partograph completeness in Makueni County. The study therefore recommends increased mobilization and routine check by supervisors to ensure partographs are filed on time and hospitals to embrace training programme to enable midwifery care-providers acquire relevant skills to complete partographs during the labour process.
\end{abstract}

Keywords: WHO Partograph, Maternity, Foetal, Outcomes

\section{Background}

Complications of labour are a significant cause of mortality, morbidity and long-term complications for both the mothers and their babies, especially in low-income settings [1]. Complicated deliveries are deleterious and cause serious psychological and physical harm to women and their families as well yet a lot of investment has been made to avert any foetal or maternal adverse outcomes [2]. Most of these negative outcomes occur mostly in the community or at primary level health facilities, where women either deliver alone or are assisted by unskilled birth attendants under unfavourable conditions for childbirth [3]. According to World Health Organization (WHO), 8\% $(42,000)$ of maternal deaths annually are as a result of obstructed labour [4]. In the developed world, obstructed labour rarely causes maternal mortality because facilities for emergency obstetric care are 
available, for example caesarean sections [5]. Whereas in the developing world, maternal deaths caused by obstructed labour are often not reported but instead the complications brought about by obstructed labour, like haemorrhage and sepsis, are reported instead, hence a wrong conclusion is made on the cause of maternal mortality [4]. Other maternal morbidities like obstetric fistula are also as a result of obstructed labour. Kenya is currently reported to have infant mortality rate of 39 deaths per 1,000 births, while the maternal mortality rate (MMR) was reported at 362 per 100,000 live births according to KDHS (2014), against the sustainable development goals (SDGs) target of less than 70 deaths per 100,000 live births and ending of needless deaths of new-borns and children below five years by the year 2030 [6]. In Makueni County, though there has been a reduction of MMR, infant mortality is still high. From January to June 2018, Makueni County reported eighty-nine (89) neonatal deaths and four (4) maternal deaths. This is a worrying trend and correct use of partograph with timely interventions would probably prevent these deaths [7]. The partograph is a graphical presentation of the progress of labour, and of foetal and maternal condition during labour and it assists birth attendants in monitoring labour [8]. Parameters like foetal heart rate, cervical dilatation, uterine contractions, pulse rate and blood pressure of the mother are plotted on the graph. This data enables the skilled birth attendant to promptly point out any deviation from the normal process and make appropriate decisions regarding the management of the mother [9]. In modern obstetric care, one of the key components is the partograph. WHO has recommended universal partograph use in labour management [10]. Compared to free written patient notes, the partograph accords birth attendants an easy method to monitor labour and communicate easily on labour progress and are able to identify complications like obstructed labour early enough before they become detrimental to the mother and the baby [11]. When used by a knowledgeable and a skilled birth attendant, it has been shown to detect deviations early and timely interventions are taken [12]. However, the major problem for improving birth outcomes is that intrapartum monitoring using the partograph is a tedious process which consumes a lot of time hence its either not used or when it's used, it's done incorrectly, leading to incorrect interpretations [13-15]. Lack of proper training including in-service training, resource shortages, high workload in relation to the staff ratios, inadequate knowledge and negative attitude like the perspective that the partograph is time consuming and redundant, among healthcare workers, have been reported as some of the issues that impede correct use of the partograph [16]. Studies conducted elsewhere and Kenya has documented insufficient and incorrect partograph use in all levels of maternity care [17]. While most barriers to partograph use are well documented, in the study area little information is available regarding the status of utilization of the partograph and the outcomes thereof [18]. This study seeks to assess the relationship between complete modified world health organization partograph and maternal and foetal outcomes in health facilities in Makueni County, Kenya.

\section{Methods}

\subsection{Study Design}

This is a quantitative cross-sectional study design.

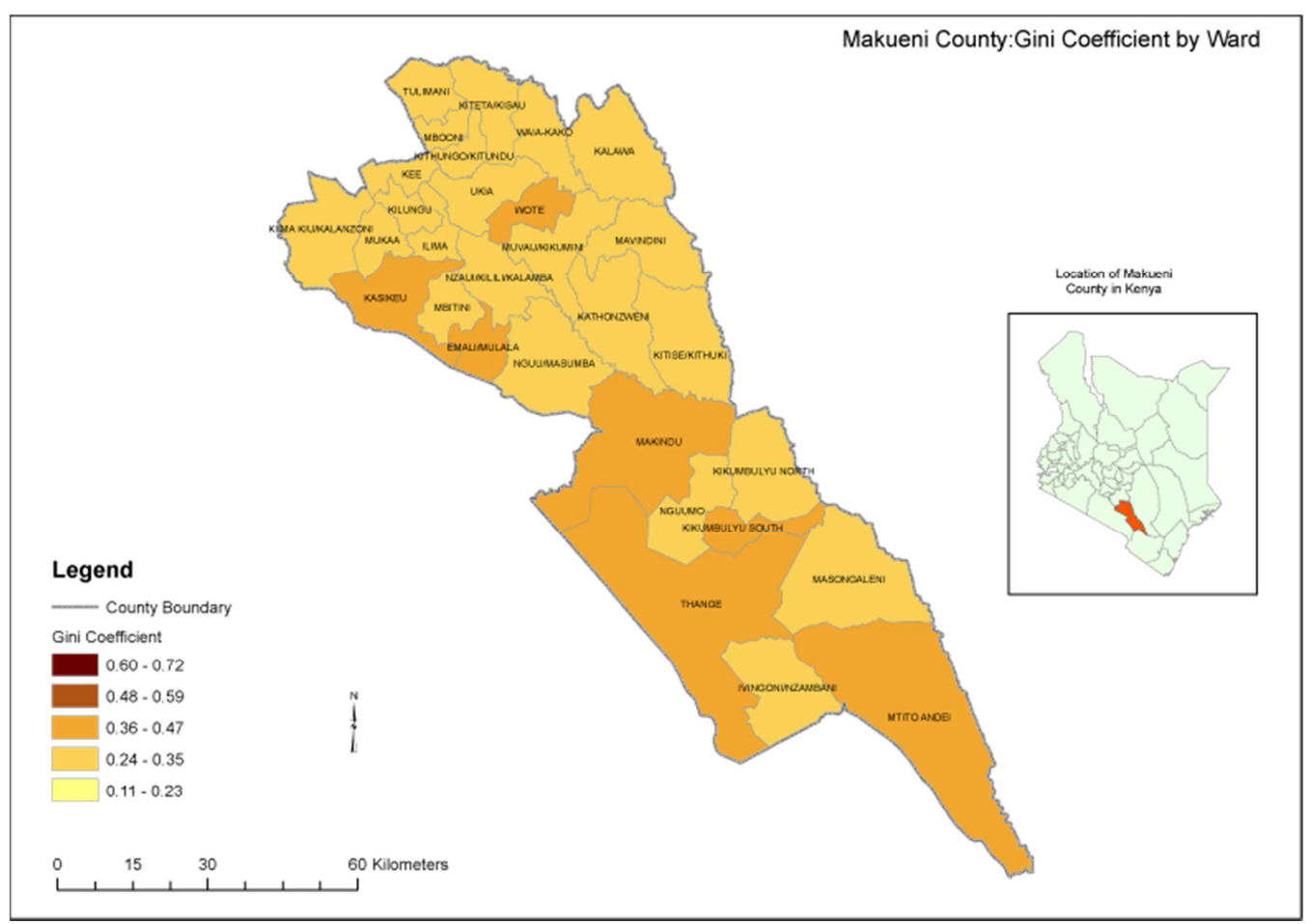

Source: Geo Names

Figure 1. Map of Makueni County. 


\subsection{Study Site}

Makueni County Referral Hospital and Makindu Sub-County Hospital both in Makueni County, Kenya formed the sites for this study. The study site was purposively chosen by the researcher, and from review of literature no study of this nature had been carried out in this area. Makueni County covers an area of $8,034.7 \mathrm{Km}^{2}$. The county lies in the arid and semi- arid zones of the eastern region of the country. The County is currently divided into six sub-counties namely Makueni, Kaiti, Kilome, Kibwezi East, Kibwezi West, and Mbooni. In the year 2012 the projected population in the county was 922,183 consisting of 449,036 males and 473,147 females. Makueni County has six sub county hospitals namely Makindu and Makueni (which are modelled as referral hospitals), Mbooni, Kilungu, Sultan Hamud, and Kibwezi west. The County also has 21 level three facilities (health centers) and 125 dispensaries. In total the County has 156 public health facilities.

\subsection{Study Population}

A retrospective review of all partographs of the deliveries conducted one month before data collection was done. The study population included all nurses and midwives who provide obstetric care in the selected health facilities.

\subsubsection{Inclusion Criteria}

Partographs for all women reporting for labour. Women admitted in labour with cervical dilatation on admission of any measure in centimetres. Pregnancy at any gestation was monitored with a partograph. Partographs for all women delivered one month before data collection. Partographs for all methods of delivery. Nurses and Midwives working in maternity wing in Makueni county referral hospital and Makindu sub county hospital, and who consented to participate in the study.

\subsubsection{Exclusion Criteria}

Nurses and Midwives who work in other departments and clients who denied to consent for data collection.

\subsection{Sampling Techniques}

Simple random sampling method was used to select the patient files to be included in the study. To select the files to be included in the study, all the files of the preceding month before data collection (May 2018) were retrieved from the registry. Sequential numbers were assigned to each of the 420 files. This formed the sampling frame. A random number generator was used to select a sample of 221 from the total files of 420 .

\subsection{Sample Size Determination}

Sample size was calculated using the formula: $\mathrm{n}=\mathrm{t}^{2} \times \mathrm{p}$ (1p) $/ d^{2}$

$\mathrm{n}=$ the required sample size for population above 10,000

$\mathrm{t}=$ the confidence level at $95 \%$ (standard value of \pm 1.96 )

$\mathrm{p}=$ the estimated proportion of the partographs used and completed, in this study it is not known and will be estimated at $50 \%$

$\mathrm{d}=$ the standard error or precision at $5 \%$ (standard value of $0.05)$

$$
\begin{aligned}
& \mathrm{n}=(1.96)^{2} \times 0.05(1-0.05) / 0.05^{2} \\
& \mathrm{n}=3.8416 \times 0.05(1-0.05) / 0.0025 \\
& \mathrm{n}=384
\end{aligned}
$$

Since the target population was less than 10,000 , required sample size is smaller and to calculate a final sample estimate, (nf) the following formulae was used;

$\mathrm{nf}=\mathrm{n} /[(1+\mathrm{n}) / \mathrm{N}]$

$\mathrm{nf}=$ desired sample size (when the population is less than 10,000)

$\mathrm{n}=$ the desired sample size (when the population is more than 10,000)

$\mathrm{N}=$ the estimation of population size

Target population per month $=420$ (average number of deliveries in the two facilities per month- Makindu hospital 220 and Makueni hospital 200 deliveries)

$\mathrm{nf}=384[(1+384) / 420]$

$\mathrm{nf}=384 /(1+0.91)$

$\mathrm{nf}=384 / 1.91$

$\mathrm{nf}=201$

$10 \%$ of $n=201$ is expected to be missing in the study, so we calculated $10 \%$ of 201 and we added to keep the study's power. This gave a total of 221. This sample was divided equally in the two facilities.

\subsection{Data Collection Tools \& Procedures}

An open-ended questionnaire was used to extract data from labour charts. A retrospective partograph review was carried out on deliveries conducted the month preceding the start of data collection. The labour ward delivery book was used to check number of deliveries. The researcher worked with data clerks to retrieve patient's files. All deliveries were included irrespective of mode of delivery and time admitted to labour ward. Data from 221 labour charts were extracted and filled in the questionnaire. Using the parameters described below, the labour charts were assessed by inspection of documentation of the parameters as filled in or not filled in (yes or no, complete or not complete). Degree to which these parameters were filled in (adequate or not adequate) was also assessed. The independent variables which were of main interest were: Foetal monitoring was assessed on FHR, status of membranes, liquor and moulding. Maternal condition was assessed on temperature, blood pressure and pulse rate. Labour progress was assessed on cervical dilatation, uterine contractions, and descent of foetal head. Alert line if crossed and action line if reached was also be assessed. Documentation of other parameters like personal details, first examination on admission, first vaginal examination, pelvic assessment, second stage of labour (date and time of delivery, method of delivery, Apgar score in 1 and 5 minutes), status of newborn, sex, weight, third stage of labour to include delivery of placenta, blood loss, completeness of placenta and membranes, state of perineum and time duration between admission in labour and delivery were assessed. The dependent (outcome) 
variables on status of mother included: method of delivery i.e. spontaneous vertex delivery (SVD), vacuum extraction (V/Ext), breech delivery and caesarean section delivery. The dependent variables on foetal outcomes included: status of baby at birth i.e. alive or dead. To weigh staff work load, data was collected from the delivery registers against the number of midwives on duty per day.

\subsection{Data Analysis}

The variables were coded, entered and analysed using SPSS version 20.0. The researcher and the statistician performed the data cleaning, clarification and quality control. Descriptive statistics and frequency tables were used to describe the extent to which the partograph was used. Chisquare test was also used to find out the association between independent variables and the dependent variables. The cut off point for the level of significance was set at $\alpha=0.05$. Phi and Cramer's $\mathrm{V}$ test was used to determine the strength of association.

\section{Findings}

\subsection{Partograph and Completeness of the Maternal, Foetal and Labour Parameters}

\subsubsection{Personal Information}

Recording of patients' name, address age and gravida was done at $99.5 \%$ while that of parity was $98.2 \%$.

\subsubsection{Admission Details}

98.2\% of partographs admission date, 95.9\% admission time, $70.5 \%$ date time of onset labour completely, $72.7 \%$ date and time membranes ruptured were completely filled and $2.7 \%$ recorded completeness in abnormal symptoms recording (table 1).

Table 1. Admission details.

\begin{tabular}{llll}
\hline & & $\mathbf{n}$ & $\mathbf{\%}$ \\
\hline \multirow{3}{*}{ Date } & Yes & 216 & 98.2 \\
& No & 4 & 1.8 \\
& Total & 220 & 100.0 \\
Time of admission & Yes & 211 & 95.9 \\
& No & 9 & 4.1 \\
& Total & 220 & 100.0 \\
& Yes & 155 & 70.5 \\
Date and time of onset labour & No & 54 & 24.5 \\
& Non-response & 11 & 5.0 \\
& Total & 220 & 100.0 \\
& Yes & 160 & 72.7 \\
& No & 44 & 20.0 \\
Date and time membranes ruptured & Not applicable & 1 & .5 \\
& Non-response & 15 & 6.8 \\
& Total & 220 & 100.0 \\
Abnormal symptoms & Yes & 6 & 2.7 \\
\hline
\end{tabular}

\begin{tabular}{lll}
\hline & $\mathbf{n}$ & $\mathbf{\%}$ \\
\hline No & 211 & 95.9 \\
Non-response & 3 & 1.4 \\
Total & 220 & 100.0 \\
\hline
\end{tabular}

\subsubsection{Examination on Admission}

$99 \%$ of the partographs had recording of the first examination of the patients. Once the first examination has been conducted on the patients, the doctor determines if to admit the patient or refer to another hospital.

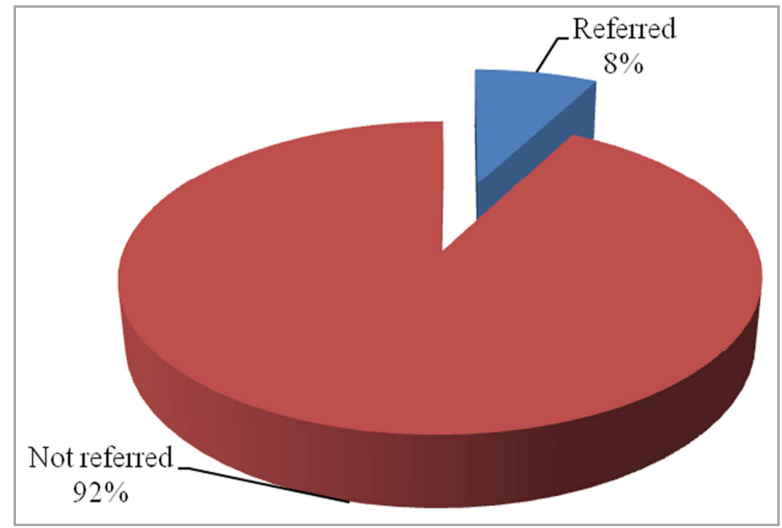

Figure 2. Patients' referral status record.

$8 \%$ were referred to other hospitals upon the first examination. The reasons for referral included meconium grade III (MG3), non-reassuring foetal status (NRFS), obstructed labour, previous scar (PSC), pre-eclampsia (PET), per vaginal (PV) bleeding, and poor progress of labour due to malposition and prolonged second stage. However, the study found that in 3 cases, the reason for referral was not indicated while in 2 cases the referral letters were missing.

\subsubsection{Foetal Monitoring}

The key elements captured in this section include; foetal heart rate, number of plotted foetal heart rate, foetal liquor, and number of plotted foetal liquor, moulding and number of plotted moulding. $92.7 \%$ of partographs had foetal heart rate record, $6.4 \%$ had not been recorded (Table 2).

Table 2. Foetal monitoring.

\begin{tabular}{llll}
\hline & & $\mathbf{n}$ & $\mathbf{\%}$ \\
\hline \multirow{4}{*}{ Foetal heart rate } & Yes & 204 & 92.7 \\
& No & 14 & 6.4 \\
& Non-response & 2 & .9 \\
& Total & 220 & 100.0 \\
\hline
\end{tabular}

Regarding the number of recorded foetal heart rates, 189 cases were plotted out of 220 with a mean of $9.21 \pm 6.31$ cases. The number of plotted cases ranged from a minimum of 1 and maximum of 28 cases (Table 3 ).

Table 3. Number of plotted foetal heart rates.

\begin{tabular}{llllll}
\hline Descriptive Statistics & & & & & \\
\hline & N & Minimum & Maximum & Mean & Std. Deviation \\
\hline Number of plotted foetal heart rates & 189 & 1 & 28 & 9.21 & 6.310 \\
Valid N (list wise) & 189 & & & & \\
\hline
\end{tabular}


$86.4 \%$ of partographs had foetal liquor recorded while $12.7 \%$ had not been recorded and only $80 \%$ of the partographs had moulding recording while $18.6 \%$ were found to have incomplete information on moulding (table 4).

Table 4. Plotting of liquor and Moulding in partographs.

\begin{tabular}{llll}
\hline & & $\mathbf{n}$ & $\mathbf{\%}$ \\
\hline \multirow{4}{*}{ Liquor } & Yes & 190 & 86.4 \\
& No & 28 & 12.7 \\
& Non-response & 2 & 0.9 \\
& Total & 220 & 100 \\
\multirow{4}{*}{ Moulding } & Yes & 176 & 80 \\
& No & 41 & 18.6 \\
& Non-response & 3 & 1.4 \\
& Total & 220 & 100 \\
\hline
\end{tabular}

\subsubsection{Labor Process}

Other component comprises of cervical dilation, descent, contractions, whether the alert line was crossed, if yes any action taken as well as the number of times each of them was plotted. With $95.0 \%$ completeness for cervical dilation, $94.5 \%$ for descent, $94.1 \%$ for contractions, $17.3 \%$ of partograph indicated that the alert line was crossed with no action taken at all. Furthermore $2.3 \%$ of action line was reached and $0.9 \%$ action taken (Table 5 ).

Table 5. Labour process indicators completeness.

\begin{tabular}{llll}
\hline & & n & \% \\
\hline \multirow{2}{*}{ Cervical dilation } & Yes & 209 & 95.0 \\
& No & 6 & 2.7 \\
\hline
\end{tabular}

\begin{tabular}{llll}
\hline & & $\mathbf{n}$ & $\mathbf{\%}$ \\
\hline \multirow{5}{*}{ Descent } & Non-response & 5 & 2.3 \\
& Total & 220 & 100.0 \\
& Yes & 208 & 94.5 \\
& No & 6 & 2.7 \\
& Non-response & 6 & 2.7 \\
Tontractions & Total & 220 & 100.0 \\
& Yes & 207 & 94.1 \\
& No & 7 & 3.2 \\
Was the alert line crossed & Non-response & 6 & 2.7 \\
& Total & 220 & 100.0 \\
& Yes & 38 & 17.3 \\
& No & 174 & 79.1 \\
& Non-response & 8 & 3.6 \\
& Total & 220 & 100.0 \\
& No & 11 & 5.0 \\
If yes any action taken & Non-response & 209 & 95.0 \\
& Total & 220 & 100.0 \\
& Yes & 5 & 2.3 \\
Was the action line reached & No & 206 & 93.6 \\
& Non-response & 9 & 4.1 \\
& Total & 220 & 100.0 \\
& Yes & 2 & 0.9 \\
& No & 1 & 0.5 \\
& Non-response & 217 & 98.6 \\
& Total & 220 & 100.0 \\
\hline
\end{tabular}

Cervical dilation, descent and contractions were distributed with a mean of $2.28,2.25,5.53$ and $\pm 0.873,0.837$ and 5.280 respectively (Table 6 ).

Table 6. Frequency of cervical dilation, Descent and Contractions plotting.

\begin{tabular}{llllll}
\hline Descriptive Statistics & & & & \\
\hline & N & Minimum & Maximum & Mean & Std. Deviation \\
\hline Cervical dilation & 209 & 1 & 6 & 2.28 & 0.873 \\
Descent & 208 & 1 & 5 & 2.25 & 0.837 \\
Contractions & 208 & 1 & 24 & 5.53 & 5.280 \\
Valid N (list wise) & 208 & & & \\
\hline
\end{tabular}

\subsubsection{Maternal Monitoring}

Blood pressure and pulse rate records for completeness was $95.0 \%$ each, while temperature record for completeness was $79.1 \%$ from the targeted institutions (Table 7 ).

Table 7. Completeness of maternal monitoring.

\begin{tabular}{llll}
\hline & & $\mathbf{n}$ & $\mathbf{\%}$ \\
\hline & Yes & 209 & 95.0 \\
Blood Pressure. & No & 9 & 4.1 \\
& Non-response & 2 & .9 \\
& Total & 220 & 100.0 \\
\hline
\end{tabular}

\begin{tabular}{llll}
\hline & & $\mathbf{n}$ & $\mathbf{\%}$ \\
\hline \multirow{3}{*}{ Pulse } & Yes & 209 & 95.0 \\
& No & 9 & 4.1 \\
& Non-response & 2 & .9 \\
Temperature & Total & 220 & 100.0 \\
& Yes & 174 & 79.1 \\
& No & 43 & 19.5 \\
& Non-response & 3 & 1.4 \\
\hline
\end{tabular}

The average number of times blood pressure was recorded was $2.34 \pm 2.439$ and the average number of times pulse rate was recorded was $5.58 \pm 5.325$ (table 8 ).

Table 8. Number of maternal monitoring records.

\begin{tabular}{lllll}
\hline Descriptive Statistics & & & \\
\hline & N & Minimum & Maximum & Mean \\
\hline Number of times blood pressure was recorded & 109 & 1 & 17 & 2.34 \\
Number of times pulse rate recorded & 109 & 1 & 23 & 5.58 \\
Valid N & 109 & & & \\
\hline
\end{tabular}




\subsubsection{First Vaginal Examination}

$100 \%$ of first information on vaginal examination was recorded

\section{(i). Second Stage of Labour}

The records of date and time of full dilatation of cervix in partographs was $80.0 \%$ completed, $98.6 \%$ of partographs had delivery date and $98.6 \%$ of delivery time was completed in partographs (table 9).

Table 9. Second stage of labour records completeness.

\begin{tabular}{llll}
\hline & & $\mathbf{n}$ & $\mathbf{\%}$ \\
\hline & Yes & 176 & 80.0 \\
Date and time of full & No & 40 & 18.2 \\
dilatation of cervix & Non-response & 4 & 1.8 \\
& Total & 220 & 100.0 \\
& Yes & 217 & 98.6 \\
Delivery date & No & 3 & 1.4 \\
& Total & 220 & 100.0 \\
& Yes & 217 & 98.6 \\
Delivery time & No & 3 & 1.4 \\
& Total & 220 & 100.0 \\
\hline
\end{tabular}

The majority of women gave birth through SVD methods (65.9\%). However, cases of $\mathrm{C} / \mathrm{S}$ accounted for $32.3 \%$ and $0.5 \%$ were breech while $1.4 \%$ were with non-response (Figure 3).

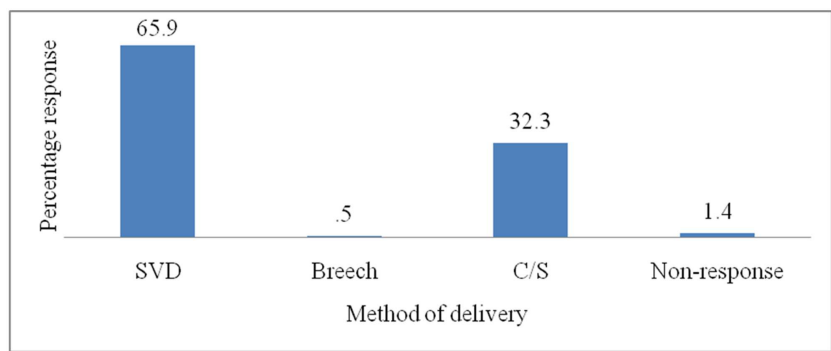

Figure 3. Method of delivery recorded in partographs.

Apgar scores were also recorded "Appearance, Pulse, Grimace, Activity, and Respiration." at 1 minute and at 5 minutes. $98.6 \%$ of the partographs had records of Apgar at 1 minute and at 5 minutes accordingly (Table 10).

Table 10. Apgar score recording.

\begin{tabular}{llll}
\hline & & $\mathbf{n}$ & $\mathbf{\%}$ \\
\hline \multirow{4}{*}{ Apgar at 1 minutes } & Yes & 217 & 98.6 \\
& Non-response & 3 & 1.4 \\
& Total & 220 & 100.0 \\
& Yes & 217 & 98.6 \\
Apgar at 5 minutes & Non-response & 3 & 1.4 \\
& Total & 220 & 100.0 \\
\hline
\end{tabular}

Among the recorded status of new born $80.0 \%$ of new born was LFT, $1.8 \%$ were premature, $0.9 \%$ was FSB and $0.5 \%$ recorded as macerated. It was noted that $16.8 \%$ partographs were not completed (Figure 4).

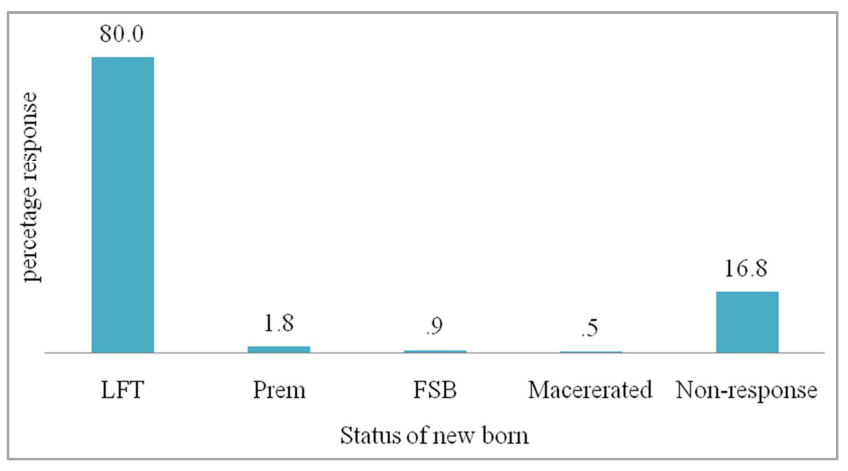

Figure 4. Status of new born.

The new-born's sex was recorded in $99.5 \%$ of the partographs, abnormalities in $50.5 \%$, weight in $99.1 \%$, length in $54.1 \%$, head circumference in $54.5 \%$ baby to nursery in $7.7 \%$ of the partographs, delivery by signature in $98.6 \%$ of the partographs (Table 11).

Table 11. New born characteristics records completeness.

\begin{tabular}{|c|c|c|c|}
\hline & & $\mathbf{n}$ & $\%$ \\
\hline \multirow{3}{*}{ Sex } & Yes & 219 & 99.5 \\
\hline & No & 1 & .5 \\
\hline & Total & 220 & 100.0 \\
\hline \multirow{3}{*}{ Abnormalities } & Yes & 111 & 50.5 \\
\hline & No & 109 & 49.5 \\
\hline & Total & 220 & 100.0 \\
\hline \multirow{3}{*}{ Weight } & Yes & 218 & 99.1 \\
\hline & No & 2 & .9 \\
\hline & Total & 220 & 100.0 \\
\hline \multirow{4}{*}{ Length } & Yes & 119 & 54.1 \\
\hline & No & 99 & 45.0 \\
\hline & Non-response & 2 & .9 \\
\hline & Total & 220 & 100.0 \\
\hline \multirow{4}{*}{ Head circumference } & Yes & 120 & 54.5 \\
\hline & No & 98 & 44.5 \\
\hline & Non-response & 2 & .9 \\
\hline & Total & 220 & 100.0 \\
\hline \multirow{4}{*}{ Baby to Nursery } & Yes & 17 & 7.7 \\
\hline & No & 201 & 91.4 \\
\hline & Non-response & 2 & .9 \\
\hline & Total & 220 & 100.0 \\
\hline \multirow{3}{*}{$\begin{array}{l}\text { Delivered by (Circle if } \\
\text { signed or not) }\end{array}$} & Yes & 217 & 98.6 \\
\hline & Non-response & 3 & 1.4 \\
\hline & Total & 220 & 100.0 \\
\hline
\end{tabular}

\section{(ii). Third Stage of Labour}

$93.2 \%$ of the partographs had information on time of delivery of placenta, $99.5 \%$ had mode of delivery record completed, 93.6\% had records on blood loss completed, $96.4 \%$ had placenta recorded completed and another $93.6 \%$ membranes record completed (Table 12).

Table 12. Third stage of labour records completeness.

\begin{tabular}{llll}
\hline & & $\mathbf{n}$ & $\mathbf{\%}$ \\
\hline \multirow{4}{*}{ Time of delivery of placenta } & Yes & 205 & 93.2 \\
& No & 14 & 6.4 \\
& Non-response & 1 & .5 \\
& Total & 220 & 100.0 \\
& Yes & 219 & 99.5 \\
& Non-response & 1 & .5 \\
& Total & 220 & 100.0 \\
\hline
\end{tabular}




\begin{tabular}{llll}
\hline & & $\mathbf{n}$ & $\mathbf{\%}$ \\
\hline \multirow{3}{*}{ Blood loss } & Yes & 206 & 93.6 \\
& No & 12 & 5.5 \\
& Non-response & 2 & .9 \\
Placenta & Total & 220 & 100.0 \\
& Completed & 212 & 96.4 \\
Membranes & Not indicated & 8 & 3.6 \\
& Total & 220 & 100.0 \\
& Completed & 206 & 93.6 \\
& Not indicated & 14 & 6.4 \\
& Total & 220 & 100.0 \\
\hline
\end{tabular}

(iii). Perineum

$78 \%$ of the partographs had the records on perineum $1 \%$ had no record and $21 \%$ had not been indicated.

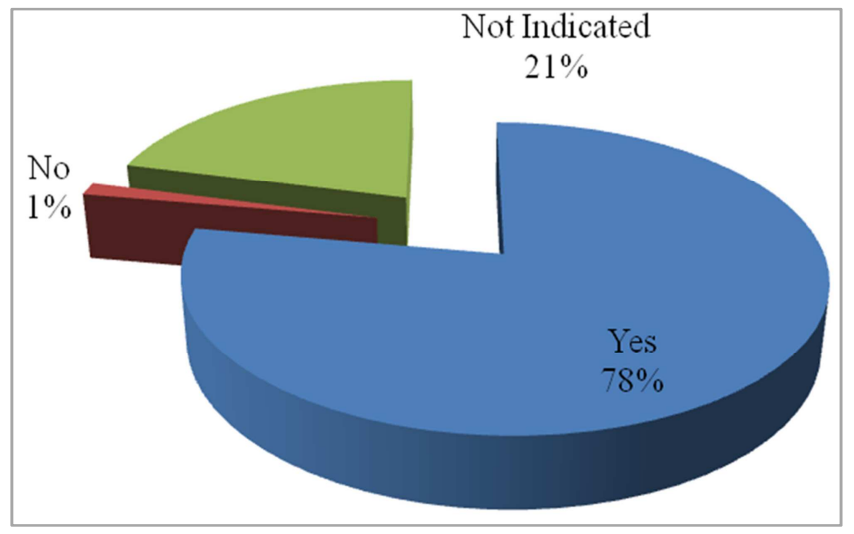

Figure 5. Completeness of perineum records.

\section{(iv). Postnatal Check}

$97 \%$ of partographs had records on postnatal check records (figure 6).

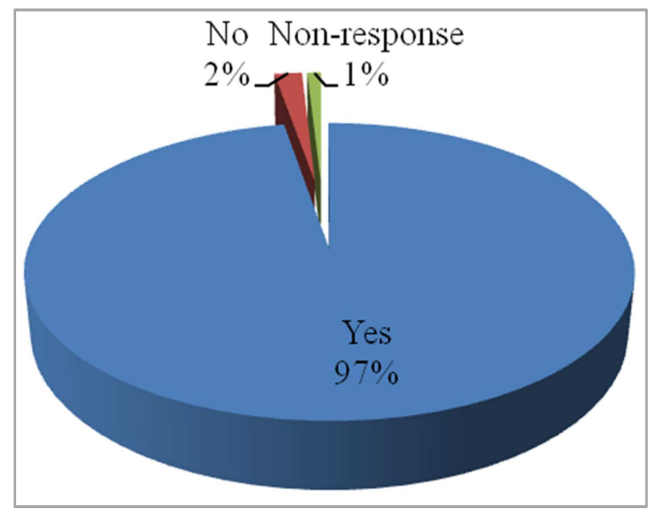

Figure 6. Completeness of postnatal records.

\subsection{Relationship Between Maternal and Foetal Outcomes to the Completeness of the Partograph}

The Who modified partograph with the explanatory variables on the three components are foetal monitoring (FHR, moulding, liquor); maternal monitoring (blood pressure, pulse, temperature); labour progress (descent, contractions, cervical dilation, crossing of alert line and reaching of action line). The maternal outcome was the methods of delivery which were SVD, breech, vacuum extraction and $\mathrm{C} / \mathrm{S}$. There was no maternal death among the partographs which were reviewed.

\subsubsection{Association Between Use of Partograph and Maternal Outcome}

Chi-square test was performed to determine association between use of the partograph and the delivery methods (SVD, C/S, Breech and Vacuum Extraction). Method of delivery had a significance association with foetal monitoring (foetal heart rate, liquor, and moulding), labour progress monitoring (descent, contractions and cervical dilatation) and referral monitoring at $\alpha=0.05$. The association between method of delivery and foetal monitoring (foetal heart rate, liquor, and moulding), labour progress monitoring (descent, contractions and cervical dilatation) and referral was found to be significantly high as indicated by Phi and Cramer's Values (foetal monitoring (foetal heart rate $=0.347$, liquor $=0.244$, and moulding $=0.242$ ), labour progress monitoring (descent $=0.254$, contractions $=0.275$ and cervical dilatation $=0.251$ ) and referral $=0.235$ ). These values imply foetal monitoring (foetal heart rate, liquor, and moulding), labour progress monitoring (descent, contractions and cervical dilatation) could help determine the appropriate method of delivery.

However, monitoring of gravida, parity, maternal monitoring (blood pressure, pulse rate and temperature) reaching of action line and crossing of action line did not have significant association with delivery method at $\alpha=0.05$. The study further noted a moderate association between method of delivery and use of partograph factors such as gravida, parity, maternal monitoring (blood pressure, pulse rate and temperature) reaching of action line and crossing of action line; these can be deduced from Phi and Cramer's values which ranged from 0.098 to 0.152 with gravida recording Phi and Cramer's value of 0.098, parity $=0.098$, maternal monitoring (blood pressure $=0.152$, pulse rate $=$ 0.152 and temperature $=0.158$ ) reaching of action line $=$ 0.102 and crossing of action line $=0.132$. The association between method of delivery and maternal monitoring tended to be slight high though not significant.

\subsubsection{Association Between Use of Partograph and Foetal Outcome}

The use of partograph had effect on the status of the new born. The baby could be born LFT, premature, FSB or macerated. There was a significant association between foetal outcome and contraction, gravidity, parity, foetal heart rate and moulding $(\alpha=0.05)$. The association was more strong between foetal outcome and gravida, parity and foetal heart rate ( $p$-value <0.01) with $99 \%$ confidence. There was existence of strong association between foetal outcome and contraction, gravida, parity, foetal heart rate and colour of liquor as shown by a Phi and Cramer's values of 0.243 , $0.495,0.496,0.505$, and 0.232 respectively. However, the association between foetal outcome and liquor, descent, cervical dilatation, crossing of alert line and the reaching of action line was not significant. Consequently, the association between foetal outcome and liquor, descent, cervical dilatation, crossing of alert line and the reaching of action line was found to be weak as implied by Phi and Cramer's 
values of $0.139,0.031,0.031,0.094$ and 0.032 respectively. The findings of this study additionally indicated a strong association between delivery method, foetal outcome and the contraction, foetal heart rate and moulding. This implies that monitoring of contraction, foetal heart rate and moulding could help anticipate the method of delivery and the status of new born.

\subsubsection{Probability of Foetal Death and Use of Partograph}

Foetal outcomes (alive or dead) were assessed against the explanatory variables (parameters on the partograph) to find the probability of foetus dying if the parameters were not monitored. The odds of delivering a dead foetus were significantly reduced by $66.7 \%$ when monitoring of FHR and liquor was done and $33.3 \%$ in monitoring moulding. Checking for state of liquor after membrane rupture also reduced the odds of foetal death by $100 \%$. Monitoring of cervical dilatation reduced the odds of foetal death by $100 \%$. It was also observed that monitoring of descent and contractions reduced the odds of foetal death by $100 \%$. The results of the study also found that where the alert line was not crossed as well as the cases where action line was not reached, no foetal death occurred. This implies that the probability that no foetal death will occur if the alert line is not crossed or action line reached was 1 .

\section{Discussion}

In order to understand the relationship between parameters, we started discussing the review of partographs and completeness of the maternal, foetal and labour. The study examined completeness of various components of partographs in Makueni county referral hospital and Makindu sub county hospital. The components of partograph examined includes personal details, admission details, examination on admission, foetal monitoring, labour process, maternal monitoring, first vaginal examination, second stage of labour, third stage of labour, perineum and postnatal check. On admission details, most of partographs had admission date, admission time date and time of onset labour and date and time membranes ruptured completely filled. However, there was little record on abnormal symptoms. There was also high completeness on examination on admission and referral cases. However, in some cases details on referral were missing. Under foetal monitoring, it was found majority of partographs had records on foetal heart rates $(92.7 \%)$, liquor $(86.4 \%)$ and moulding recorded but low plotting $(80 \%)$. Labour process record is another component of partograph that was found important for this study. Majority of partograph had records on cervical dilation $(95 \%)$, descent $(94.5 \%)$, contractions $(94.5 \%)$ and low record on reaching of action. It was also noted that number of time the plotting of cervical dilation, descent and contractions were distributed with a mean of $2.28 \pm 0.873,2.25 \pm 0.837,5.53 \pm 0.828$. The results of this study noted the completion rate on labour process, maternal monitoring, first-vaginal examination, second-stage of labour, third-stage of labour, perineum and postnatal check were adequately completed in most of partographs. These results are higher than those of a Ghanaian study [19] whereby parameters pertaining to the progress of labour (contractions, cervical dilatation and descent) recording to standard occurred in 55-60\% of cases. In Accra (Ghana) [13] it was found out that only $25.6 \%$ were recorded to standard while in an Ethiopian study, cervical dilatation, uterine contractions and descent were recorded to standard in $32 \%, 21 \%$ and $6.9 \%$ respectively [20]. In at least $40 \%$ of cases in this study, abnormal/slow progress could not have been identified since parameters pertaining to labour progress were not recorded as expected. These results point out the lack of understanding of what the partograph is designed for. Of the parameters pertaining to Foetal wellbeing (heart rate, moulding and nature of liquor), foetal heart rate was recorded properly in about half of cases. The other parameters were recorded to standard in about a third of cases. A study in Ethiopia [21] also revealed that in 73 (30.5\%) partograph forms, foetal heart rates were not totally recorded and the documentation were substandard in $59(24.7 \%)$ and standard in 107 (44.8) partograph forms. The finding further revealed that moulding for the great majority $(94.1 \%)$ of partograph forms were not recorded, and $11(4.6 \%)$ partographs were documented to substandard and $3(1.3 \%)$ to standard level. For the relationship between maternal and foetal outcomes to the completeness of the partograph, the method of delivery had a significance association with foetal monitoring (foetal heart rate, liquor, and moulding), labour progress monitoring (descent, contractions and cervical dilatation) and referral monitoring $(\alpha=0.05)$. The association between method of delivery and foetal monitoring (foetal heart rate, liquor, and moulding), labour progress monitoring (descent, contractions and cervical dilatation) and referral was found to be significantly high. There was a significant association between foetal outcome and contraction, gravidity, parity, foetal heart rate and moulding $(\alpha=0.05)$. The study found that the association was more strong between foetal outcome and gravida, parity and foetal heart rate $(\mathrm{p}<0.01)$. The study further noted existence of strong association between foetal outcome and contraction, gravida, parity and foetal heart rate. The odds of delivering a dead foetus were significantly reduced by $66.7 \%$ when monitoring of FHR and liquor was done and $33.3 \%$ in monitoring moulding. Checking for membrane rupture also reduced the odds of foetal death by $100 \%$. This is in contrast with a study done in Ethiopia [19] which showed that the odds of foetal deaths and use of partograph had a weak association. The odds of foetal deaths were reduced by $59.5 \%$ when proper monitoring of the FHR was done. Monitoring of cervical dilatation reduced the odds of foetal death by $100 \%$. It was also observed that monitoring of descent and concentrations reduced the odds of foetal death by $100 \%$. The study also found that where the alert line was not crossed as well as the cases where action line was not reached, no foetal death occurred. 


\section{Conclusion}

The study concludes that most of midwifery care-providers partially filled partographs. The study further concludes that there exist a significant association between partograph completeness and maternal, foetal outcomes and labour progress in Makueni County. This implies in cases where maternal, foetal outcomes and labour progress is positive, there is high likelihood of having a properly filled partograph filled. The study recommends increased mobilization and routine check by supervisors to ensure partographs are filed on time. The study recommends assessing the effects of utilization of the modified world health organization (WHO) partograph on quality of maternal health.

\section{Ethical Considerations}

Ethical approval was sought from Kenyatta University Research Ethics Committee. Research permit was applied from the National Commission for Science, Technology and Innovation (NACOSTI). Approval by the County administration and Hospital Management Teams of the various hospitals was also sought. Informed written consent was obtained from each study participants, before the data collection exercise. Any personal identification of the study participants was not recorded during data collection. Confidentiality of information was observed by keeping the questionnaires and data in a lockable place. Data collected was used for the purpose of this study only.

\section{Further Research}

The study recommends further research to assess documentation of partograph by using direct observation method of data collection to avoid report bias as well as to make sure whether the filled partograph forms are filled appropriately or not at the spot.

\section{Policy Implications}

The results of this study will help health care leaders of the county to focus on completeness of the partograph by initiating trainings of health workers on impact of completeness of a partograph if the county is committed to reduce the burden of maternal and infant mortality in Makueni County.

\section{Authors Contributions}

UMM conceptualized the study, developed the proposal and drafted the final report. MGN reviewed the proposal and guided UMM throughout the study. MS reviewed the methodology and the final report.

\section{Funding}

This study did not receive any fund. Authors were the only source of funds.

\section{Conflict of Interest}

Authors declare no conflict of interest.

\section{References}

[1] Khan, K. S., Wojdyla, D., Say, L., Gulmezoglu, A. M., Van Look, P. F. WHO analysis of causes of maternal death: a systematic review. Lancet. 2006; 367 (9516): 1066-74.

[2] Monchari, R., Nangulu, A. K., \& Broerse, J. E. W. Perceived causes of adverse pregnancy outcomes and remedies adopted by Kalenjin women in ruralKenya, 2018, 5, 1-16.

[3] Kone, S., Hurlimann, E., Baikoro, N., Dao, D., Bonfoh, B., Goran, E. K. N., ...Jaeger, F. N. (2018). Pregnancy-related morbidity and risk factors for fatal foetal outcomes in the Taabo health and demographic surveillance system, Cote d'Ivoire, 2018 1-14.

[4] Mathai, M. The partograph for the prevention of obstructed labor. Clinical Obstetrics and Gynecology, vol. 52, no. 2, pp. 256-269, Jun. 2009.

[5] Echoka, E. Makokha, A, Nyandieka, L \& Byskov, J. L. Barriers to emergency obstetric care services: accounts of survivors of life threatening obstetric complications in Malindi District, Kenya, $2014 \quad 17$ (Supp 1), 15-20 https://doi.org/10.11694/pamj.supp.2014.17.1.3042.

[6] Ochako, R., \& Gichuhi, W. Pregnancy wantedness, frequency and timing of antenatal care visit among women of childbearing age in Kenya. Reproductive Health, 2016 1-8. https://doi.org/10.1186/s12978-016-0168-2.

[7] Nyongesa, C. et al. 'Factors influencing choice of skilled birth attendance at ANC: evidence from the Kenya demographic health survey'. BMC Pregnancy and Childbirth, 2018 362, pp. 4-9.

[8] Anokye, R. et al.'Use and completion of partograph during labour is associated with a reduced incidence of birth asphyxia: a retrospective study at a peri-urban setting in Ghana'. Journal of Health, Population and Nutrition, 2019 7, pp. 1-8.

[9] Souza, J. P., Oladapo, O. T., Bohren, M. A., Mugerwa, K., Fawole, B., Moscovici, L., ... WHO BOLD Research Group. The development of a Simplified, Effective, Labour Monitoring- to- Action (SELMA) tool for Better Outcomes in Labour Difficulty (BOLD): study protocol. Reproductive health, 2015 12, 49. doi: 10.1186/s12978-015-0029-4.

[10] World Health Organization. Programme Budget 2012-2013 Mid-Term Review Report, 2013.

[11] Kabakyenga, J. K., Östergren, P. O., Emmelin, M., Kyomuhendo, P., \& Odberg Pettersson, K. The pathway of obstructed labour as perceived by communities in southwestern Uganda: a grounded theory study. Global health action, 2011 4, doi: 10.3402/gha.v4i0.8529.

[12] Ansari, N., Manalai, P., Maruf, F., Currie, S., Stekelenburg, J., van Roosmalen, J., ... Tappis, H. Quality of care in early detection and management of pre- eclampsia/eclampsia in health facilities in Afghanistan. BMC pregnancy and childbirth, 201919 (1), 36. doi: 10.1186/s12884-018-2143-0. 
[13] Gans-Lartey, F., O’Brien, B. A., Gyekye, F. O., \& Schopflocher, D. The relationship between the use of the partograph and birth outcomes at Korle-Buteaching hospital. Midwifery. 2013; 29 (5): 461-7.

[14] Levin, K. \& Kabagema, J. Use of the partograph: effectiveness, training, modifications, and barriers. Engender health, 2011.

[15] United Nations. The Millennium Development Goals Report. pp. 1-80, Jun. 2010.

[16] Qureshi, Z. P., Sekadde-Kigondu, C. \& Mutiso, S. M. Rapid assessment of partograph utilization in selected maternity units in Kenya, East African Medical Journal, vol. 87, no. 6, pp. 235-241, Jun 2010.

[17] Lavender, T., Omoni, G., Lee, K., Wakasiaka, S., Watiti, J., \& Mathai, M. Students' experiences of using the partograph in Kenyan labour wards. African Journal of Midwifery and Womens' Health, 2011 vol. 5, no. 3, pp. 117-122.
[18] Zelellw, D. A., \& Tegegne, T. K. Level of partograph utilization and its associated factors among obstetric caregivers at public health facilities in East Gojam Zone, Northwest Ethiopia. PloS one, 201813 (7), e0200479. doi: 10.1371/journal.pone.0200479.

[19] Opoku BK \& Nguah SB. Utilization of the modified WHO partograph in assessing the progress of labour in a metropolitan area in Ghana. Res J of Womens Health. 2015; 2: 2.

[20] Yisma et al. Knowledge and utilization of partograph among obstetric care givers in public health institutions of Addis Ababa, Ethiopia. BMC Pregnancy and Childbirth 2013 13: 17. doi: 10.1186/1471-2393-13-17.

[21] Bogale D. and Markos M. Knowledge of obstetric danger signs among child bearing age women in Goba district, Ethiopia: a cross-sectional study. BMC Pregnancy and Childbirth, 2015 15: 77 DOI 10.1186/s12884-015-0508-1. 